\title{
Rosenthal fibers as a diagnostic marker craniopharyngioma, an intraoperative study
}

\author{
Martha Lilia Tena-Suck ${ }^{1}$, Andrea Yosajany Morales del Ángel ${ }^{2}$, Lilia Edith Corona ${ }^{3}$, Armando Saúl \\ Ruiz-Treviño ${ }^{4}$, Ángel Vagas-Sánchez ${ }^{4}$, Laura E. Estrada-Natoli ${ }^{5}$ \\ 1. Department of Neuropathology, National Institute of Neurology and Neurosurgery, México City, México. 2. Laboratory \\ of Nanotechnology, National Institute of Neurology and Neurosurgery, México City, México. 3. Department of Pathology, \\ General Hospital of Occident, Zapopan Jalisco, México. 4. Service of Neurosurgery, National Institute of Neurology and \\ Neurosurgery, México City. México. 5. CITOCAP, General Hospital Ángeles Del Pedregal, México City, México.
}

Correspondence: Martha Lilia Tena-Suck. Address: Department of Neuropathology, National Institute of Neurology and Neurosurgery "Manuel Velasco Suárez", Av Insurgentes Sur 3877 Col. La Joya, DelegaciónTlalpan, Mexico City, Mexico. E-mail: mltenasuck@gmail.com

Received: January 9, 2015

Accepted: March 15, 2015

Online Published: March 25, 2015

DOI : $10.5430 /$ crcp.v2n3p36

URL: http://dx.doi.org/10.5430/crcp.v2n3p36

\section{Abstract}

Craniopharyngioma is a sellar tumor with cystic and solid structures. The cystic areas contain aproteinaceous material described as "oil machinery", little is known about the characteristics of this fluid. We studied a woman 60 years old with a long history of 10 years with visual disturbance until amaurosis. The MRI showed a sellar lesion. Intraoperative findings showed a necrotic yelloswish material with purulent appearance that was diagnosed as abscess. The intraoperative study with crush smears showed a dirty background with necrosis and lipo-proteinaceous material. Few inflammatory cells and abundant Rosenthal fibers formation were also observed. Epithelial cells were lacking. The presence of Rosenthal fibers and lipo-proteinaceous material has been observed in the boundary of this tumor, but those findings have been described as the same and may be helpful for the craniopharyngioma diagnosis. The presence of these indicates rupture of the cystic structure and conditions the output of the material that is damaging normal brain structures.

\section{Key words}

Craniopharyngioma, Rosenthal fibers, Tumor boundary, Intraoperative study, Smears

\section{I ntroduction}

Craniopharyngiomas (CPs) are epithelial tumors that typically arise in the suprasellar region of the brain. CPs are benign but locally invasive tumours of the sellar region that can be divided as two subtypes. The adamantinomatous type (aCP) occurs mainly during childhood and the papillary type (pCP) - is found almost exclusively in adults, according the WHO classification ${ }^{[1]}$.

Chemical meningitis (CM) is a rare mechanism due to the rupture of craniopharyngioma cyst; it occurs because of the presence of cholesterol crystals in cyst fluid secreted by the squamous epithelium lining of the cyst. 
Depending in the cholesterol contents of cystic tumor fluid, spontaneous rupture may be presented with or without meningitis ${ }^{[2-4]}$.

The cyst rupture mechanism cyst depends on the cyst wall weakness. It is caused by cyst expansion that conditions cyst wall degeneration ${ }^{[2]}$. Cystic forms of CPs are studied biochemically regarding lactate, $\mathrm{pH}$, total protein, albumin, immunoglobulin's $\mathrm{G}$ and M contents. The CPs' pathogenesis seems to be more similar to the other brain tumors than what earlier it was believed to be ${ }^{[5]}$.

The aim of this paper is to present a case report of craniopharyngioma that was diagnosed as probable abscess in the parasellar region, but the macroscopic appearance and intraoperative smears analysis section showed only Rosenthal fibers and proteinaceous material.

\section{Case report}

A 60-year-old woman has a long history of headache and visual disturbance of ten years. The lastest clinical manifestation when she presented to our institution was left amaurosis. The MRI showed a sellar mass. She was operated. During the surgical process, there was a soft and necrotic yellowish fluid appearance and was diagnosed as abscess (see Figure 1). The blood was easily extended and had grainy aspect and was taken with H\&E stain. Intraoperative crush smears showed a necrotic, dirty, lipo-proteinaceous background (see Figure 2a \& 2b). There were few cells, inflammatory type (see Figure 2b), and amorphous eosinophilic material similar to Rosenthal fibers (see Figure 2c). Macrophages with lipid vacuole were also observed (see Figure 2d). This eosinophilic material are formed by these irregular and amorphous structures that show lipid vacuoles inside (see Figure 3a-3c) and few epithelial cell with lipid vacuoles were observed (see Figure 3d). It was diagnosed at the boundary of craniopharyngioma and definitive diagnosis was craniopharyngioma.
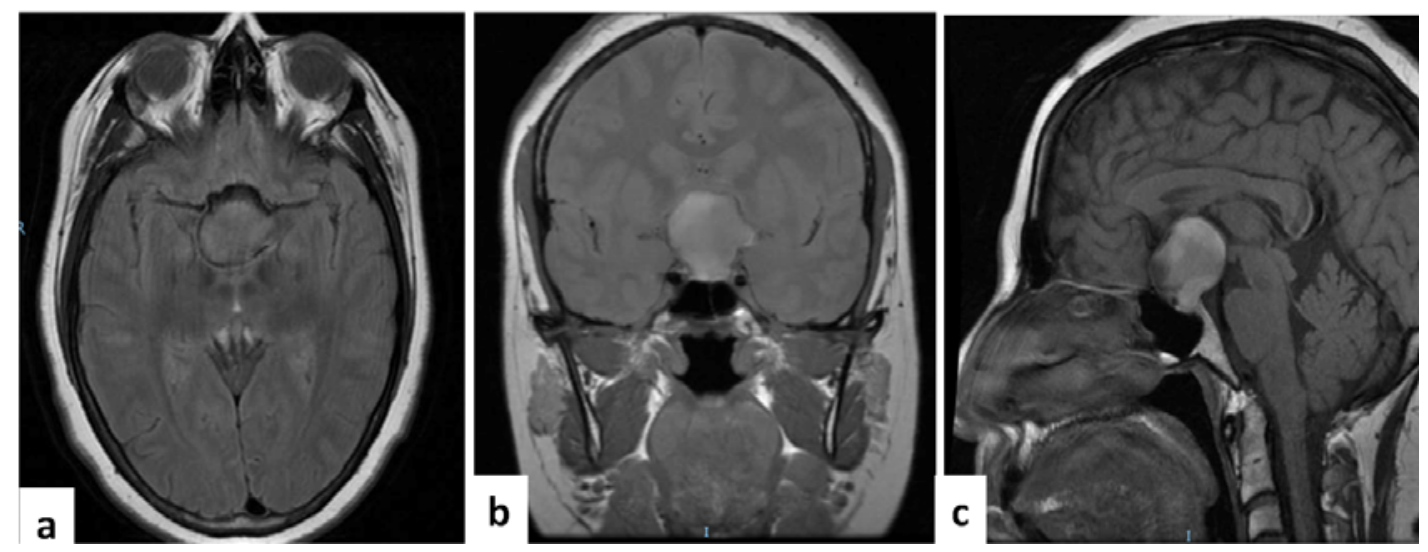

Figure 1. IRM of the lesion. (a) In sagittal image showed a supraselar enhancement mass, (b) T1: iso- to hyper intense to brain (due to high protein content machinery oil cysts), and (c) with the signal intensities of the mixed cystic and solid components.

\section{Discussion}

Chemical meningitis presence depends on the cholesterol contents of cystic fluid. They have been reported from several types of cystic lesions such as: dermoids epidermoid cysts in the cerebellar pontine angle cisterns, cysts of Rathke pouch, cholesteatoma following radical mastoidectomy and remnant after geniculate ganglion surgery. Cerebral vasospasm can be caused by the cyst rupture. Its well-known chemical meningitis should be considered as a differential diagnosis even in postoperative periods of craniopharyngioma. Long-term follow-up is necessary to evaluate cyst recurrence. $\mathrm{CP}$, Rathke's cyst (RC), and xanthogranuloma $(\mathrm{XG})$ are akin rare sellar masses formed by a purulent, yellowish soft material ${ }^{[2-4]}$. 

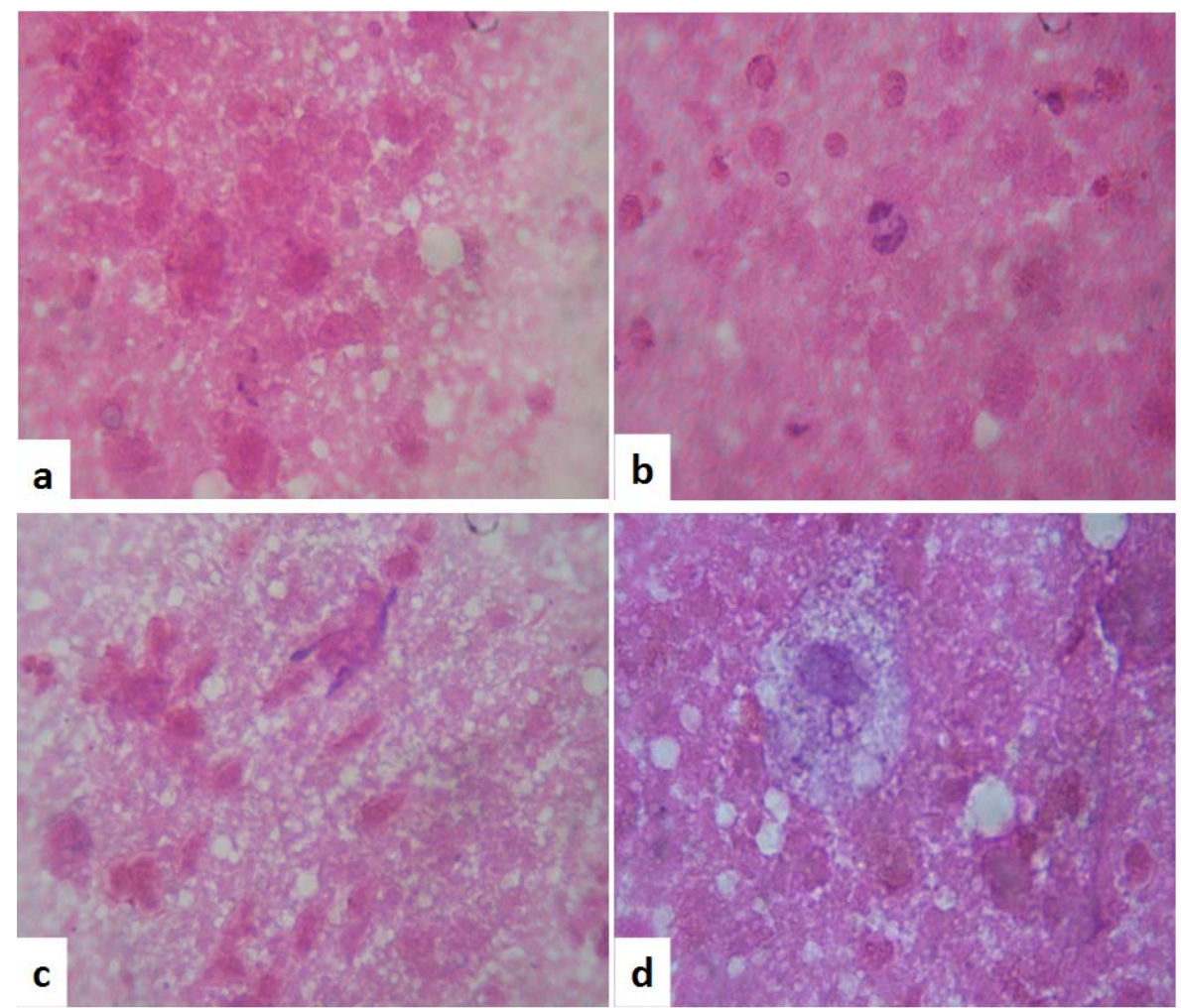

Figure 2. The intraoperative crush smears showed a necrotic, dirty, lipoproteinaceus background (a) and (b) showed few inflammatory cells, (c) this amorphous eosinophilic material that they were considerate as Rosenthal fibers showed lipid vacuole insides and Macrophages with lipid vacuole were observed in (d).
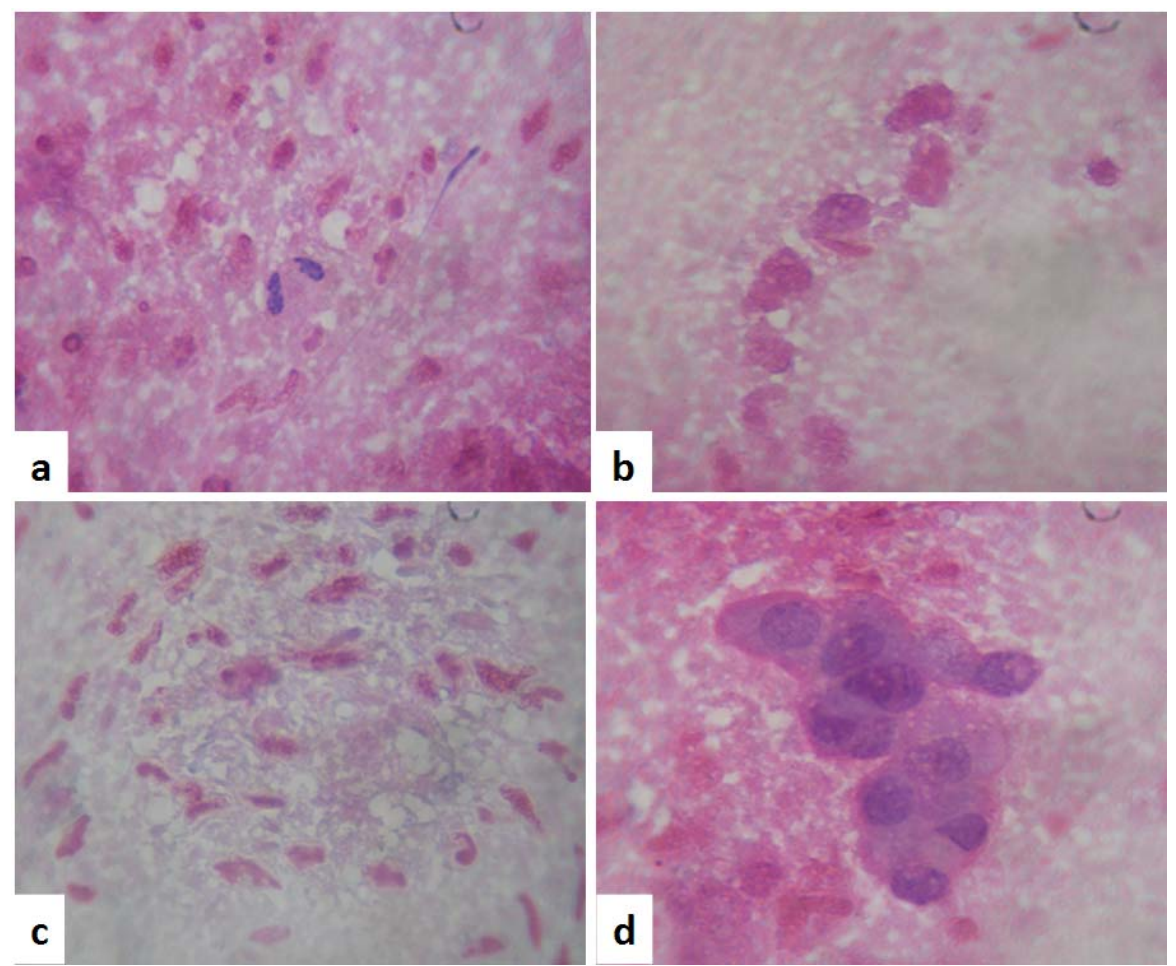

Figure 3. (a) and (b). Eosinophilic material was formed by these irregular and amorphous structures that show lipid vacuoles inside. (c) This amorphous precipitates become denser and in (d) few epithelial cell with lipid vacuoles and necrotic appearance were observed. 
Rosenthal fibers (RFs) have been described in the periphery or boundary of craniopharyngioma but little is known about it. RFs are inclusions within astrocytes, presented not only in Alexander's disease ${ }^{[5]}$, also in astrocytic tumors, glial scar tissue ${ }^{[6]}$ and Rosenthal Fibers encephalopathy ${ }^{[7]}$. They are granular deposits, intimately associated with intermediate filaments ${ }^{[6]}$.

Alexander's disease (AxD) is characterized by eosinophilic cytoplasmic inclusions, termed Rosenthal fibers, within astrocyte processes but near to demyelination areas ${ }^{[6]}$. Rosenthal fibers contain glial fibrillary acidic protein (GFAP), the heat shock proteins hsp-27, ubiquitin, and $\alpha \beta$-crystallin. It is postulated they are formed by a metabolic disturbance of astrocytes that leads excessive amounts degradation of glial filaments ${ }^{[5]}$.

Rosenthal fibers encephalopathy is distinguished by a preponderance of Rosenthal fibers in the brain stem without demyelination or accompanying clinical evidence of a debilitating systemic illness caused by a neurological involvement ${ }^{[6]}$.

RFs have seen surrounding brain parenchyma showing marked reactive lipoid gliosis ${ }^{[7]}$. The basic principles of gliosis causes an astrocytic reaction in different CNS diseases as brain tumors, demyelinating disease, meningitis, and also to no glial tumors such as craniopharyngioma, hemangioblastomas, metastases, and lymphomas. New diagnostic methods have facilitated differences between reactive astrocytosis and diffuse gliomas ${ }^{[7]}$. The presence of pilocytic astrocytes and Rosenthal fibers in the gliosis tissue around a slow-growing falx meningioma is an additional evidence for a peculiar type of changes in the astrocytes. The challenge in the routine practice of surgical neuropathology is to distinct the reactive astrocytosis, which can be caused by non-neoplastic and neoplastic conditions, including a low-grade infiltrating diffuse astrocytoma, WHO grade II ${ }^{[1]}$. This can be analyzed with small biopsies, limited amounts of tissue, for pathologic study, especially considering it may be helpful to make differences in the patient's prognosis and therapy ${ }^{[7]}$.

Pilomyxoid astrocytomas are identified as the most aggressive variant of pilocytic astrocytomas which are common in infants and young children ${ }^{[1]}$. Pilomyxoid astrocytomas have some characteristics like: a perivascular arrangement of pilocytic cells with a homomorphous architecture, and an elongated and uniformed bipolar cells loosely ranged within a prominent myxoid background ${ }^{[8]}$.

\section{Conclusion}

Presence of a dirty, necrotic and lipo-proteinaceous background and Rosenthal fibers is not indicative of craneofaringioma but is helpfully to make diagnosis of craniopharyngioma in intraoperative smears.

\section{References}

[1] A Perry, DN Louis, BW Scheithauer, et al. In: Louis DN, Ohgaki H, Wiestler OD, Cavenee WK, editors. WHO Classification of Tumours of the Central Nervous System. Lyon, France: IARC Press; 2007. 164-72p.

[2] N Shida, N Nakasato, K Mizoi, et al. Symptomatic vessel narrowing caused by spontaneous rupture of craniopharyngioma cyst. Case report. Neurol Med Chir (Tokyo). 1998; 38: 666-668. http://dx.doi.org/10.2176/nmc.38.666

[3] R Stendal, TA Pietila, K Lehmann, et al. Ruptured intracranial dermoid cysts. Surg Neurol. 2002; 57: 391-398. http://dx.doi.org/10.1016/S0090-3019(02)00723-1

[4] IA Arefyeva, JB Semenova, MS Zubairaev, et al. Analysis of fluid in craniopharyngioma-related cysts in children: proteins, lactate and pH. ActaNeurochir (Wien). 2002; 144: 551-4. PMid: 12111487. http://dx.doi.org/10.1007/s007010200077

[5] T Iwaki, A Iwaki, J Tateishi, et al. Alpha B-crystallin and 27-kd heat shock protein are regulated by stress conditions in the central nervous system and accumulate in Rosenthal fibers. Am J Pathol. 1993; 143: 487-95. PMid: 8393618.

[6] SP Wilson, S Al-Sarraj, LR Bridges. Rosenthal fiber encephalopathy presenting with demyelination and Rosenthal fibers in a solvent abuser: adult Alexander's disease? Clin Neuropathol. 1996; 15: 13-16. PMid: 8998849.

[7] M Rivera-Zengotita, AT Yachnis. Gliosis versus glioma? Don't grade until you know. Adv Anat Pathol. 2012; 19: 239-49. PMid: 22692287. http://dx.doi.org/10.1097/PAP.0b013e31825c6a04

[8] DW Fults, JJ Townsend, WT Couldwell. Spontaneous hemorrhage associated with a pilomyxoid astrocytoma. Case report. J Neurosurg. 2003; 99: 416-20. PMid: 12924720. http://dx.doi.org/10.3171/jns.2003.99.2.0416

Published by Sciedu Press 